\title{
Synthesis of new chelating ion exchange resins derived from guaran and divinylbenzene styrene copolymer for selective adsorption of metal ions
}

\author{
Kalpa Manda $1^{1}$, Sameer Vyas ${ }^{2}$, Swati Vyas ${ }^{3}$ \\ ${ }^{1}$ Department of Chemistry, Dyal Singh College, University of Delhi-110003, India \\ ${ }^{2}$ Central Soil and Materials Research Station, New Delhi-110016, India
}

\begin{abstract}
New chelating ion exchange resin containing hydroximate of 5 amino salicylic acid was synthesized by incorporating it in divinylbenzene styrene (DVBS) copolymer. Hydrophilic polysaccharidematrix ofguaran was also used to incorporate hydroximate of 5 amino salicylic acid in it. The resin characteristics were studied by determining its bulk density, specific bulk volume, moisture content, degree of substitution and ion exchange capacity. The resin was characterized by means of IR spectra, Nitrogen content and $p H$ titration. The distribution coefficient values of different metal ions namely $\mathrm{Fe}(I I), \mathrm{Cu}(I I), \mathrm{Zn}(\mathrm{II}), \mathrm{Cd}(\mathrm{II}), \mathrm{Co}(\mathrm{II})$, Ni(II), $\mathrm{Ca}(I I), U(V I), C r(V I) \& W(V I)$ was carried out on these resins as a function of $p H$. Metal analysis was done by Atomic Absorption Spectrophotometer. The hydroximate derivative of guaran is found to be more selective than that of diving benzene co-polymer.
\end{abstract}

Key Words:Adsorption. Coefficient, DVB Styrene, Distribution, Guar gum,

\section{Introduction:}

The chelating ion exchange resins have wide range of application in different areas. Their application based on their synthesis containing different functional groups and reagents. The functionalized polymers containing specific functional groups have wide spread applications. ${ }^{1-2}$ They have been used in biological systems, synthesis of pencillin ${ }^{3}$,immobilization enzyme ${ }^{4}$, application of dyes ${ }^{5}$, ion exchange as substrate carrier ${ }^{6}$, as protecting group ${ }^{7}$, in isolation or removal of interfering ions, separation of electrolytes from non-electrolytes ion and in the preparation of high purity water etc.

Chelating resins from chelate complexes with metal ions instead of undergoing ion exchange process. They have been reported for their extensive use in separation and concentration of metal ions ${ }^{8-12}$. They are useful in mineral processing industries as float aids, depressants, flocculants and collectors. Chelax 100 has been reported to be extensively used .Chelax 100 resin (styrene divinylbenzenecopolymer containing iminodiacetic acid) is used for preconcentration and separation of rare earth and heavy metals in $\mathrm{pH}$ range of 6-8 but they exhibit the disadvantage that the affinity of resins for alkaline earth metal is similar to that of transition ions.

Chelax 100 and Dowex A-1 are also used for collection of trace element $\mathrm{Cd}, \mathrm{Zn}, \mathrm{Pb}, \mathrm{Co}, \mathrm{Cu}, \mathrm{Fe}, \mathrm{Mn}$, $\mathrm{U}, \mathrm{V}$ and Au from sea water ${ }^{13}$. All these amino poly carboxylic acid containing chelating resins are not enough selective and that their efficiency is reduced due to their ability to form stable complexes with alkaline earth metals. With the aim of synthesizing selective chelating resins which require no pretreatment of the sample for concentration, which do not form stable complexes with alkaline earth metals and also useful in hydrometallurgical process specially in mineral processing as floatacids. We tried to synthesize chelating resins containing hydroximates of amino hydroxyl carboxylic acid, 5 amino salicylic acid hydroximate in DUB styrene and in guar have been synthesized.

\section{Experimental:}

All chemicals used were of A R grade.Guaran powder (200 mesh size) was obtained from local guar gum industry. Chloromethylated DVBS with $4 \%$ crosslinking was procured from Thermax Pvt. Ltd. 5 amino salicylic acid, epichlorohydrin and hydroxylamine hydrochloride were obtained from Sisco chemical industries, Bombay were solvents were distilled before use.Infrared spectra of the synthesized resins were recorded on Shimadzu IR-400 spectrophotometer using $\mathrm{KBr}$ pellets. Kjeldahl method was used for analysis of Nitrogen. Metal ions were estimated using Perkin elmer-2380 atomic absorption spectrophotometer.

\subsection{Synthesis of Resins}

\subsubsection{Preparation of epoxyether of guaran.}

$486 \mathrm{~g}$ of guaran powder (a galctomannon from the seeds of cyanaposestetragonalobus) was slurried with dioxine. $50 \%$ aqueous sodium hydroxide was added to guaran gradually to render the reaction mixture alkaline. The contents of the flask wasslurried magnetically at $45^{\circ} \mathrm{C}$ for 2 hours. One more of 
epichlorohydrinwas added to the flask with continuous stirring. The $\mathrm{pH}$ of reaction mixture was adjusted between $9-10$, and stirring continued for another 4 hours at $45^{\circ} \mathrm{C}$. The compound was filtered on vacuum pump and washing was done with $80 \%$ aqueous methanol containing nitric acid. This epoxy ether of guaran was further used for derivatisation (scheme 1)

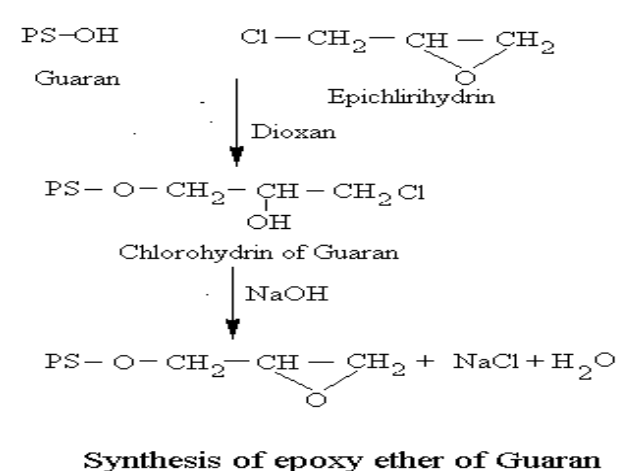

\subsubsection{Synthesis of Guaran 5 amino Salicylic acid Hydroximate: \\ Scheme-1}

This was done in three steps

(a) Preparation of methyl ester of 5- Amino salicylic acid: $15.3 \mathrm{~g}$ (0.1 mole) of 5 Amino salicylic acid was taken in a $250 \mathrm{ml}$ round bottom flask to the acid excess methanol was added then dry HCL gas was passed till the saturation was complete. The reaction mixture was reflexed for 3 hours on mantle. The methyl ester of 5 Amino salicylic acid was formed.

(b) Synthesis of hydroximate of 5 Amino salicylic acid.:8.35 g (0.05 mole) of methyl ester of 5 Amino salicylic acid and methanolic solution of $3.49 \mathrm{~g}(0.05 \mathrm{~mole})$ hydroxylamine hydrochloride were stirred on magnetic stirrer for 5 hours in a round bottom flask at $30^{\circ} \mathrm{C}$. The $\mathrm{Ph}$ of reaction mixture was adjusted by sodium methylate to $\mathrm{Ph}$ 9.2-9.3. The hydroxamic acid of 5 amino salicylic acid was formed which was filtered obn Buchner funnel and wasned with $80 \%$ methanol solution.

(c) Incorporation of hydroxamate of 5 Amino salicylic acid in guar.: $3.36 \mathrm{~g}(0.02 \mathrm{~mole})$ of hydroxamic acid of 5 Amino salicylic acid was taken in $10 \mathrm{ml}$ methanol and stirred at $45^{\circ} \mathrm{C}$ for 5 hour. During the process of stirring $4.86 \mathrm{~g}$ ( $0.01 \mathrm{~mole})$ of epoxy ether of guaran was added. The producer formed was filtered and the resin formed was successively treated with $0.1 \mathrm{~N} \mathrm{HCL}, 0.1 \mathrm{~N} \mathrm{NaOH}$ and $0.1 \mathrm{~N}$ HCL. The resin was finally washed with absolute alcohol and dried in vacuum (scheme 2).

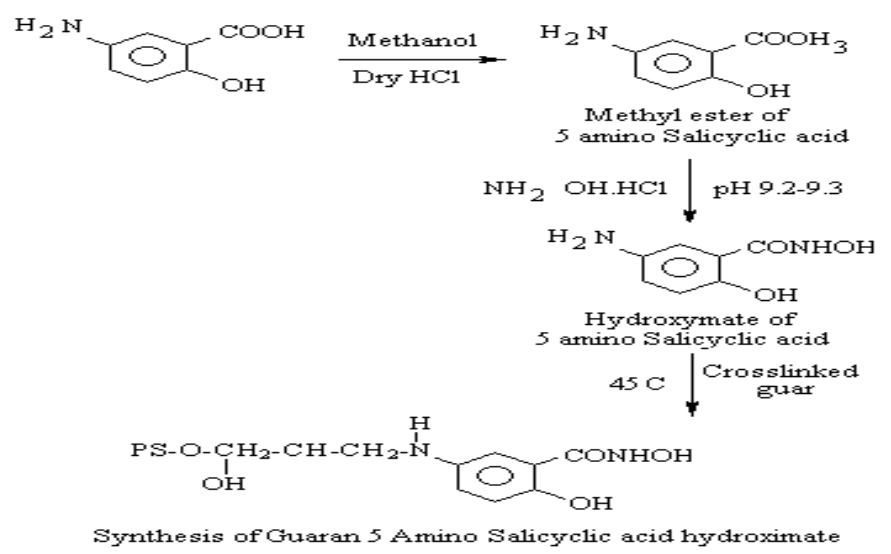

Scheme-2

\subsubsection{Synthesis of 5 Amino salicylic acid hydroximate in DVB styrene:}

This was also done in three steps:

(a) Preparation of methyl ester of 5- Amino salicylic acid: same procedure was followed as mentioned in section 1

(b) Incorporation of ester in DVB styrene. : $5.714 \mathrm{~g}$ (0.02 mole) of chloromethylated beads in DVB -styrene were taken and soaked over night in DMF for swelling. The swelled resin was taken in a round bottom flask $16.7 \mathrm{~g}$ (0.1 mole) of methyl ester of 5 Amino salicylic acid and dissolved in DMF. This was added to round bottom flask containing beads to the reaction mixture $8.4 \mathrm{~g}(0.1 \mathrm{~mole})$ of sodium bicarbonate was 
added slowly. The reaction mixture was refluxed with water condenser on a water bath at $70^{\circ} \mathrm{C}$. Few porcelain pieces were added to the reaction mixture to avoid bumping during the reaction the reaction. The reaction mixture was then refluxed for 8 hours. The product was filtered on Buchner funnel and washed with hot distilled water followed by methanol.

(c) Synthesis of hydroximate of 5 Amino salicylic acid: The above filtered product was taken in round bottom flask. To this methanolic solution of $6.9 \mathrm{~g}(0.1 \mathrm{~mole})$ hydroxyl amino hydrochloride was added. The reaction mixture was then refluxed with water condenser on water bath for 5 hours. To this reaction mixture sodium methylate was added to adjust $\mathrm{pH}$ between 9.2-9.3 This was again refluxed for 5 hours. Product formed was filtered on Buchner funnel washing was done with $80 \%$ aqueous methanol containing few drops of nitric acid to remove excess alkali. The resin was successively treated with $0.1 \mathrm{~N} \mathrm{HCL}, 0.1 \mathrm{~N}$ $\mathrm{NaOH}$ and $0.1 \mathrm{~N}$ HCL. The final washing was done with methanol and product was dried under vacuum.(Scheme 3)

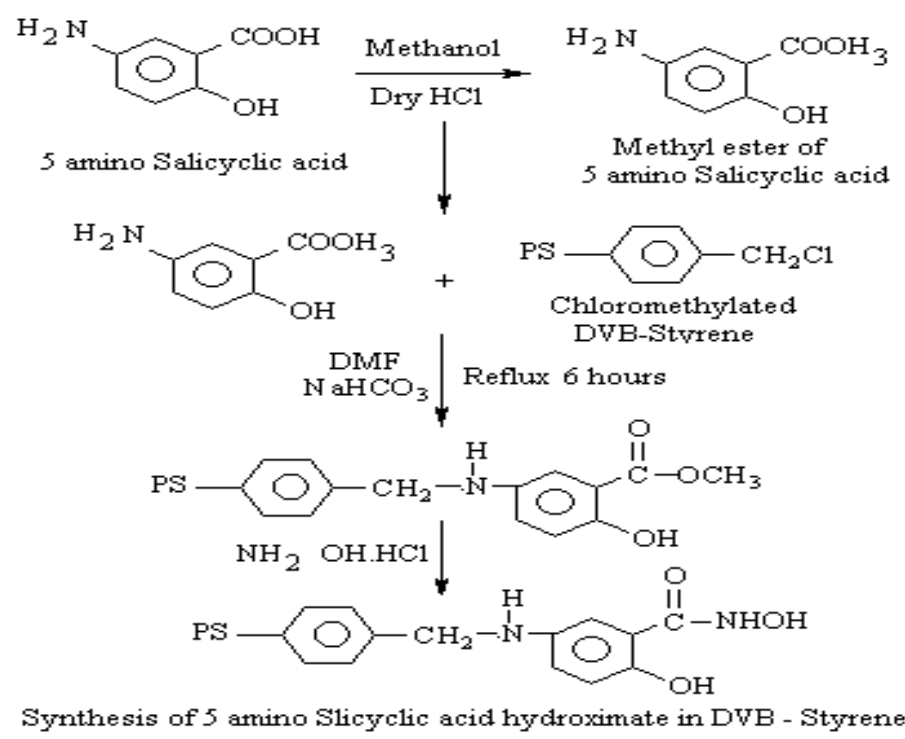

\section{Scheme-3}

\section{Determination of distribution coefficients:}

The molar distribution coefficients ' $\mathrm{Kd}$ ' of metals showing pronounced adsorption on chelating resins is $\mathrm{Cu}(\mathrm{II}), \mathrm{Fe}(\mathrm{II}), \mathrm{Zn}(\mathrm{II}), \mathrm{Co}(\mathrm{II}), \mathrm{Cd}(\mathrm{II}), \mathrm{Ni}(\mathrm{II}), \mathrm{Ca}(\mathrm{II}), \mathrm{Cr}(\mathrm{VI}), \mathrm{W}(\mathrm{VI}), \mathrm{U}$ (VI) were determined by batch method. Weighed amount of resin $(1 \mathrm{~g})$ in hydrogen form were placed in glass stopped conical flasks containing $1 \mathrm{ml}$ of $1000 \mathrm{ppm}$ metal ion solution and a known volume $(40 \mathrm{ml})$ of $(0.2 \mathrm{~m})$ sodium acetate-acetic acid buffer of varying $\mathrm{pH}$ (4-7). The contents were stirred magnetically for $10 \mathrm{hrs}$ at $25^{\circ} \mathrm{C}$. The two phases after equilibrium were separated by filtration and an aliquot of filtration was analyzed for metal concerned by atomic absorption spectrophotometer.

The calibration curves for different metals were plotted by analyzing a series of standard solutions of metal ions. The unknown concentration was determined from these curves. The distribution coefficient value 'Kd' was completed using the formula.

$$
\mathrm{Kd}=\frac{\text { Amount of metal in resin / } \mathrm{g} \text { of dry resin }}{\text { Amount of metal in solution / } \mathrm{mL} \text { of solution }}
$$


Resin characteristics:

Table 1:

\begin{tabular}{|l|l|l|l|l|}
\hline \multicolumn{1}{|c|}{ Resin } & $\begin{array}{l}\text { Moisture } \\
\text { Content } \mathbf{( \% )}\end{array}$ & $\begin{array}{l}\text { Bulk Density } \\
\mathbf{g} / \mathbf{c m}^{3}\end{array}$ & $\begin{array}{l}\text { Specific } \\
\text { Volume } \mathbf{~ c m}^{\mathbf{3}} / \mathbf{g}\end{array}$ & $\begin{array}{l}\text { Nitrogen Content } \\
(\%)\end{array}$ \\
\hline ASAH-G & 16.54 & 0.714 & 1.40 & 1.44 \\
ASAH-DVB & 8.33 & 0.641 & 1.56 & 1.63 \\
\hline
\end{tabular}

Table 2:

Kd value of different metal ions on G-ASAH

\begin{tabular}{|l|l|l|l|l|l|l|l|l|l|}
\hline $\mathbf{p H}$ & $\mathbf{F e}(\mathbf{I I})$ & $\mathbf{C u}(\mathbf{I I})$ & $\mathbf{Z n}($ II) & $\mathbf{C d}(\mathbf{I I})$ & $\mathbf{C o}(\mathbf{I I})$ & $\mathbf{N i}(\mathrm{II})$ & $\mathbf{U}(\mathbf{V I})$ & $\mathbf{C r}(\mathrm{II})$ & $\mathbf{W}(\mathbf{V I})$ \\
\hline 4 & 657 & 207 & 1686 & 598 & - & 194 & 207 & 1962 & 889 \\
\hline 4.64 & 850 & 269 & 1734 & 613 & - & 230 & 306 & 2326 & 1483 \\
\hline 5 & 1000 & 471 & 1792 & 624 & 146 & 301 & 366 & 3270 & 2553 \\
\hline 5.5 & 3555 & 841 & 1761 & 634 & 556 & 341 & 666 & 2158 & 4455 \\
\hline 6 & 9741 & 225 & 1757 & 700 & 385 & 426 & 841 & 1792 & 6832 \\
\hline 6.5 & 899 & 150 & 1742 & 748 & 139 & 279 & 254 & - & 3266 \\
\hline 7 & - & - & - & 691 & - & - & - & - & - \\
\hline
\end{tabular}

Table 3:

Kd values of different metal ions on ASAH-DVBS

\begin{tabular}{|lccccccccc|}
\hline $\mathbf{p H}$ & $\mathbf{F e}(\mathbf{I I})$ & $\mathbf{C u}(\mathbf{I I})$ & $\mathbf{Z n}(\mathbf{I I})$ & $\mathbf{C d}(\mathbf{I I})$ & $\mathbf{C o}(\mathbf{I I})$ & $\mathbf{N i}(\mathbf{I I})$ & $\mathbf{U}(\mathbf{V I})$ & $\mathbf{C r}(\mathbf{I I})$ & $\mathbf{W}(\mathbf{V I})$ \\
\hline 4 & 1186 & 351 & 1706 & 596 & -- & 222 & 231 & 2064 & 1025 \\
4.64 & 1788 & 740 & 1786 & 665 & -- & 279 & 333 & 2353 & 1891 \\
5 & 3662 & 910 & 1824 & 681 & 363 & 345 & 648 & 3402 & 2974 \\
5.5 & 8385 & 1405 & 1778 & 692 & 728 & 443 & 766 & 2173 & 6220 \\
6 & 5911 & 648 & 1758 & 716 & 388 & 540 & 910 & 1792 & 6837 \\
6.5 & 4722 & 498 & 1562 & 766 & 181 & 363 & 549 & -- & 23247 \\
\hline
\end{tabular}

IV. Result And Discussion

In the IR spectra of guaran 5 amino acid hydroximate resin, a band was observed at $3400 \mathrm{~cm}^{-1}$ which was assigned to N-H mode while another broad band at $3000-2800 \mathrm{~cm}^{-1}$ was ascribed to $\mathrm{O}-\mathrm{H}$. The $\mathrm{C}=\mathrm{O}$ stretch vibration of hydroxamic acid appeared at $1670 \mathrm{~cm}^{-1}$. The $\mathrm{C}-\mathrm{O}$ peak of carboxylic acid near 1580 and $\mathrm{C}=\mathrm{O}$ band of ester near $1725 \mathrm{~cm}^{-1}$ disappeared in spectra ofdihydroxamic acid derivative.

The moisture content, bulk density, specific bulk volume and N content of G ASAH and ASAH BVB are in table $1 \& 2$.

\section{Conclusion}

\section{Sorption studies of various metal ions by the resins}

The molar distribution studies of various metal ions viz. Fe(II), $\mathrm{Cu}(\mathrm{II}), \mathrm{Zn}(\mathrm{II}), \mathrm{Cd}(\mathrm{II}), \mathrm{Co}(\mathrm{II}), \mathrm{Ni}(\mathrm{II})$, $\mathrm{Ur}(\mathrm{VI}), \mathrm{Cr}(\mathrm{VI}) \& \mathrm{~W}(\mathrm{VI})$ with the newly synthesized resins G-ASAH and ASAH-DVBS are given in table 2 \& 3 respectively. The data indicate that the values of distribution coefficientfirst increases, attains a maxima and then finally decreases with increasing $\mathrm{pH}$.

In case of guaran 5-amino salicylic acid hydroximate, the resin shows maximum adsorption at $\mathrm{pH} 5$ for $\mathrm{Zn}(\mathrm{II}) \& \mathrm{Cr}(\mathrm{VI})$ ions . $\mathrm{Fe}(\mathrm{II}), \mathrm{Ni}(\mathrm{II}), \mathrm{U}(\mathrm{VI})$ and $\mathrm{W}$ (VI) show maximum adsorption at $\mathrm{pH}$ 6. $\mathrm{Cu}$ (II) and $\mathrm{Co}$ (II) show maximum adsorption at $\mathrm{pH} 5.5$ while $\mathrm{Cd}$ (II) adsorbs maximum at $\mathrm{pH}$ 6.5. At the $\mathrm{pH}$ of maximum adsorption the selectivity order of various metal ions on this resin are as follows:

$\mathrm{Fe}$ (II) $>\mathrm{W}$ (II) $>\mathrm{Cr}$ (VI) $>\mathrm{Zn}$ (II) $>\mathrm{U}$ (VI) $>\mathrm{Cu}$ (II) $>\mathrm{Cd}$ (II) $>\mathrm{Co}$ (II) $>\mathrm{Ni}$ (II)

$\begin{array}{lllllllll}9741 & 6832 & 3270 & 1792 & 841 & 840 & 748 & 556 & 426\end{array}$

The data suggests that the resin shows good efficiency for Fe (II). The Kd value is over ten times the value for metals like $\mathrm{Cu}$ (II), $\mathrm{Cd}$ (II), $\mathrm{Co}$ (II) and $\mathrm{Ni}$ (II). So this resin can easily be used for the separation of $\mathrm{Fe}$ from $\mathrm{Ni}$ at $\mathrm{pH}$ 6, W (VI) from $\mathrm{U}(\mathrm{VI})$ also $\mathrm{pH}$ 6. With the resin 5-amino salicylic acid hydroximate DVB styrene, 
the results are comparable to the Guaran counterpart. Here also the resin shows high absorbance with Fe (II) at $\mathrm{pH} 5.5$.

\section{References}

[1]. Shah B.A., Shah A.V., Bhandari B.N., Study of chelating ion exchange resin containing 8-hydroxy quinoline and separation of metal ions by selectiveon the resin column, Asian J. Chem., 13, 1305-1311, 2001.

[2]. Shah B.A., Shah A.V., Bhandari B.N., Selective elution metal ions on a newchelating ion exchange resin derived from substituted 8-hydroxy quinoline,Asian J. Chem., 15, 117-125, 2003.

[3]. A.Patchornik, M.Fridkin and E.Katchalsky, German patent 1913,488 ; chem. Abstr72(1970)

[4] . A.Akelah and D.C.Sherington, chem..Rev, 81,(1981) 557

[5]. A.S Lindrey, Rev.Macromool.chem 4 (1970)1

[6] . T.M Suzuki, T.Yokoyama, H.Matsunage and .Kimura, .Bull.chem.soc.japan 59

[7]. J.Brown and R.E.Willams,can.J.Chem.,49(1971)8765

[8]. P.Hodge and J.waterhouse, J.Chem.soc.perkinTrans.I, 10(1983) 2319

[9] . J. Dengman, Jr.S,Siggia,C.Barton and K.B HiscockAnal.chem,44(1972)1351

[10]. E.M.Moyers and J.B.Fritz Anal Chem 49(1977)418

[11]. C, W Blount, D.E Leyden T.L Thomas and S,Mguill, Anal Chem 45 (1973) 1045

[12]. S.Bohra, R.Mathur, N.K Mathur and P.N Mathur, J.Polymer Material 9 (1992)101

[13]. LedynEtal [D.E. Leydon, T.A. Patterson and J.J. Alberts and Chem. 47 (1975) 733 